\title{
Patients teaching patient safety: the challenge of turning negative patient experiences into positive learning opportunities
}

\section{Antonia S Stang, ${ }^{1}$ Brian M Wong ${ }^{2}$}

${ }^{1}$ Departments of Pediatrics and Community Health Sciences, University of Calgary, Alberta Children's Hospital Research Institute, Calgary, Alberta, Canada

${ }^{2}$ Department of Medicine, Sunnybrook Health Sciences Centre, Centre for Quality Improvement and Patient Safety (C-QuIPS), University of Toronto, Toronto, Ontario, Canada

\section{Correspondence to}

Dr Brian M Wong, Department of Medicine, Sunnybrook Health Sciences Centre, University of Toronto, 2075 Bayview Avenue, Room H466, Toronto, Ontario, Canada M4N 3M5;

BrianM.Wong@sunnybrook.ca

Accepted 6 October 2014 Published Online First 24 October 2014

\section{SLinked}

- http://dx.doi.org/10.1136/ bmjqs-2014-002987

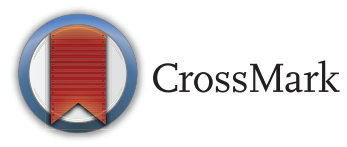

To cite: Stang AS, Wong BM. BMJ Qual Saf 2015;24:4-6.
Educators have long relied on the use of patient cases to illustrate key patient safety concepts to learners. ${ }^{1-3}$ These efforts engage clinician learners by harnessing the tradition of clinically based educational fora, such as morbidity and mortality rounds and other such case conferences. Teaching about the systems approach to patient safety in the context of compelling cases-a patient taken for someone else's invasive cardiology procedure, or a patient who died after her arterial line was flushed with insulin instead of heparin ${ }^{1}{ }^{4}$-will have more impact than just outlining the Swiss cheese model of accident causation and describing the human factors perspective in investigating critical incidents.

Engaging as these case-based approaches to teaching patient safety may be, they tend to focus on the more 'technical' aspects of patient safety such as teamwork and communication, principles of human factors engineering or the different stages of the medication management process in which errors can arise. Lost in such learning sometimes is the patient perspective, the voice that emphasises the importance of keeping the patients and families central to conversations about patient safety. More recently, published accounts of patient and provider stories relate their personal experiences with patient safety incidents. ${ }^{5-7}$ However, having actual patients tell their stories and interact directly with learners is a novel educational approach for patient safety training that warrants consideration for several important reasons.

\section{ENGAGING PATIENTS IN TEACHING PATIENT SAFETY: AN APPEALING PROSPECT}

First, there is an obvious appeal to involving patients and families in health professions education because they provide an authentic perspective on avoidable harm resulting from patient safety incidents. Beyond that however, their involvement may serve to address some important challenges that educators face when implementing a patient safety educational programme. Some programmes struggle to make leaning about patient safety engaging or interesting, or find that learners fail to see the relevance of patient safety because it seems intangible. Patients recounting their own experiences with harm from patient safety incidents serve in a very real way to make this content relevant.

Second, many programmes lack faculty capacity to teach patient safety. ${ }^{8} 9$ This common problem reflects the relative newness of the field of patient safety relative to other topics taught in health professions education. Using patients as trainers may help to address this problem to a certain degree as well-creating learning experiences around patient stories and analysing these events makes for robust, experiential learning that may avoid the need for a large number of trained faculty. Recruiting patients for a role normally reserved for trained faculty may also serve to model patient engagement, providing a very visible example of patients playing a more active role in healthcare system redesign and advancing our training of future health professionals.

Despite the obvious ideological appeal, health professions educators to date have not significantly involved patients or families in the design or delivery of patient safety training. ${ }^{9}{ }^{10}$ In this issue of $B M J$ Quality and Safety, however, ${ }^{11}$ Jha et al evaluated their novel curriculum using patient narratives and discussions facilitated by the patients or carers who had 
experienced harm during healthcare. They compared this approach with a more traditional method of using expert faculty to teach patient safety. Although the authors did not find a difference between the two groups in the primary outcome-attitudes towards patient safety-they did report a difference in the shortterm emotional response to the patient stories using the Positive and Negative Affective Schedule score (a reliable and validated questionnaire assessing mood and emotional engagement in terms of emotional state). This 20-item survey assesses emotional state by asking learners to rate 10 items on the positive affect scale (eg, interested, enthusiastic, inspired) and 10 items on the negative affect scale (eg, distressed, hostile, guilty). Interestingly, they found that the intervention group had significantly higher positive and negative affect scores. These findings offer important insights into the benefits and potential challenges associated with the use of patients for patient safety education.

\section{OPTIMISING LEARNING OUTCOMES WHEN ENGAGING PATIENTS IN TEACHING PATIENT SAFETY}

Not surprisingly, when learners hear heartfelt, emotionally charged stories about patient safety incidents told directly by patients who experienced them, the potential for negative emotions is real. It is not entirely clear based on the findings of the study by Jha et al why learners experienced negative emotions, although one could hypothesise several potential explanations. Perhaps the narratives invoked memories of personal experiences with errors that junior learners encountered during their training-they might even remind learners of patient safety incidents experienced as patients or family members themselves. Alternatively, the patient narrative may blur the line between advocacy and activism. While it is important that learners acknowledge the critical role that patients play as advocates for better care, a strongly worded call for change from patients might have the unintended effect of making learners uncomfortable about their role in a healthcare system that has failed patients and families. Or, it is possible that these stories unmask individual challenges that learners possess with respect to empathy that preclude them from exhibiting an appropriate emotional response.

Whatever the reason, it is important to consider the impact of these negative emotions on learners when involving patients in safety training in medical education. While one might assume that evoking negative emotions is undesirable, the discussions and reflections that follow, if properly facilitated, could help learners to gauge their emotional response and demonstrate a greater degree of empathy to future patients when patient safety incidents occur. Therefore, understanding broadly the role of emotion on learning may inform future efforts to properly prepare faculty, trainees and patients for these learning encounters.
Within medical education, researchers have begun exploring the role of emotion and stress on learning in the context of high fidelity simulation. ${ }^{12-14}$ High fidelity simulation training can have an emotional impact on participants, however the impact of this on performance and learning outcomes has been conflicting. Results from a recently published randomised control trial showed that emotions were more negative for students in training groups where the simulated patient dies, and that these students also reported increased cognitive load and had poorer learning outcomes. ${ }^{13}$ Conversely, another study reported that simulation with added emotional stressors led to greater anxiety during advanced cardiac life support instruction but correlated with enhanced performance of advanced cardiac life support skills after this course. ${ }^{12}$ These conflicting findings suggest that emotional reactions on the part of learners have the potential to inhibit, and to enhance, learning outcomes. This highlights the need to anticipate learners' positive and negative affective reactions, and to develop strategies to optimise the potential for a positive impact on learning outcomes.

One potential strategy to address the emotional impact and optimise the learning experience is to incorporate 'postexperience analysis' or debriefing. One of the most important determining factors for the overall effectiveness of a simulation experience is the quality of the briefing and debriefing that occur before and after the simulation. ${ }^{15} 16$ It may be wise to extend the key lessons learned from simulation debriefing to inform the effective use of patients in patient safety training. Educators should tailor briefing and debriefing to the learning objectives for the session. They also need to create a supportive climate with an environment of trust by acknowledging the vulnerability of the participant. For example, faculty will likely need to forewarn students and brief them on the potential negative emotional responses that can arise before they hear a patient narrative about their experiences with patient safety incidents. Debriefing the narrative is equally important, with explicit attention paid to equipping residents with a healthy approach to managing their negative emotional responses. Finally, the individual doing the debriefing must be trained and skilled in facilitation. So in fact, involving patients to teach about patient safety requires faculty members that possess a unique combination of patient safety teaching skills, the ability to effectively incorporate the use of narrative as a pedagogical approach, and experience with debriefing. This unfortunately will add to the current burden of faculty development demands with respect to patient safety education.

\section{SAFEGUARDING PATIENTS AND FAMILIES}

Although the study by Jha et al only measured the emotional state of the learners, one would anticipate that the patients and families would experience emotional reactions from their roles as well. We are unaware of any existing research on the emotional impact of teaching patient 
safety on the patient and family, however existing work in the realm of simulated patients suggests that there are also positive and negative effects associated with performing a patient role. ${ }^{17-19}$ Positive effects reported by standardised patients (SPs) included development of a more balanced view of health professionals, better communication skills and becoming more tolerant of others. ${ }^{19}$ Examples of negative physical, psychological and behavioural symptoms reported by SPs included fatigue, dissatisfaction with own or others' performance, nervousness, anxiety about things that might happen during the performance and anxiety about the patient role. ${ }^{17} 18$

We hope that patients and families would also experience positive outcomes from their engagement in patient safety teaching. However, we must also be prepared for the possibility of negative emotional and psychological effects from retelling their adverse healthcare experiences, as well as anxiety and nervousness with respect to their teaching role and interaction with learners. Strategies to reduce the negative impacts of portraying patient roles on SPs may be relevant to patients and families involved in teaching patient safety, including; (1) providing a standby SP who can fill in when other SPs need a break; (2) encouraging SPs to turn down roles they are uncomfortable with; (3) change or adjust patient roles after a period of time; and (4) provide more frequent or improved feedback training to give SPs more confidence in giving feedback to students. ${ }^{18}$ These strategies for safeguarding SPs highlight the importance of acknowledging the potential emotional impact on patients and families engaged in patient safety education, and the need to provide them with the flexibility, support and tools to minimise the negative impact. These findings, combined with the literature on simulation debriefing, emphasise the importance of training patients and families, in patient safety content, and in developing skills to effectively facilitate discussions and provide appropriate feedback to learners.

\section{CONCLUSION}

It seems evident that before educators broadly engage patients and families in patient safety training, they will need to: (1) know more about the link between the affective impact of patient narratives and long-term learner outcomes; and (2) develop strategies to mitigate potential negative emotional and cognitive impacts on the learner and the patient or family. One suggestion would be to borrow from more well-established educational approaches, such as the use of high-fidelity simulation and SPs, to inform the patient training and faculty development requirements needed to maximise learning outcomes. Understanding exactly how these elements factor into the planning and delivery of patient safety education that involves patient narratives needs further attention, and will rely on a broad range of study methodologies that extend beyond traditional experimental designs. Future research must also focus on better understanding and mitigating the potential harms that patients experience as trainers. Only then can we be confident that we are optimising the use of patient narratives to deliver the best possible patient safety training to our learners.

Contributors ASS and BMW: Conception, drafting and revision of article, final approval of version to be published.

Competing interests None.

Provenance and peer review Not commissioned; internally peer reviewed.

\section{REFERENCES}

1 Bates DW. Unexpected hypoglycemia in a critically ill patient. Ann Intern Med 2002;137:110-16.

2 Shojania KG, Fletcher KE, Saint S. Graduate medical education and patient safety: a busy--and occasionally hazardous--intersection. Ann Intern Med 2006;145:592-8.

3 Wachter RM, Shojania KG, Markowitz AJ, et al. Quality grand rounds: the case for patient safety. Ann Intern Med 2006;145:629-30.

4 Chassin MR, Becher EC. The wrong patient. Ann Intern Med 2002;136:826-33.

5 Levinson W, Shojania KG. Bad experiences in the hospital: the stories keep coming. BMJ Qual Saf 2011;20:911-13.

6 Liao JM, Thomas EJ, Bell SK. Speaking up about the dangers of the hidden curriculum. Health Aff (Millwood) 2014:33:168-71.

7 Martin Bromiley "Just a Routine Operation” http://www. institute.nhs.uk/safer_care/general/human_factors.html

8 Headrick LA, Baron RB, Pingleton SK, et al. Teaching for quality: integrating quality improvement and patient safety across the continuum of medical education. Washington, DC: Association of American Medical Colleges (AAMC), 2013.

9 Wong BM, Etchells EE, Kuper A, et al. Teaching quality improvement and patient safety to trainees: a systematic review. Acad Med 2010;85:1425-39.

10 Boonyasai RT, Windish DM, Chakraborti C, et al. Effectiveness of teaching quality improvement to clinicians: a systematic review. JAMA 2007;298:1023-37.

11 Jha V, Buckley H, Gabe R, et al. Patients as teachers: a randomised controlled trial on the use of personal stories of harm to raise awareness of patient safety for doctors in training. BMJ Qual Saf 2015;24:21-30.

12 Demaria S, Jr, Bryson EO, Mooney TJ, et al. Adding emotional stressors to training in simulated cardiopulmonary arrest enhances participant performance. Med Educ 2010;44:1006-15.

13 Fraser K, Huffman J, Ma I, et al. The emotional and cognitive impact of unexpected simulated patient death: a randomized controlled trial. Chest 2014;145:958-63.

14 Price JW, Price JR, Pratt DD, et al. High-fidelity simulation in anesthesiology training: a survey of Canadian anesthesiology residents' simulator experience. Can J Anaesth 2010;57:134-42.

15 Fanning RM, Gaba DM. The role of debriefing in simulation-based learning. Simul Healthc 2007;2:115-25.

16 Rall M, Manser T, Howard SK. Key elements of debriefing for simulator training European. JAnaesthesiol 2000;17:516-17.

17 Bokken L, van Dalen J, Rethans JJ. Performance-related stress symptoms in simulated patients. Med Educ 2004;38:1089-94.

18 Bokken L, van Dalen J, Rethans JJ. The impact of simulation on people who act as simulated patients: a focus group study. Med Educ 2006;40:781-6.

19 Woodward CA, Gliva-McConvey G. The effect of simulating on standardized patients. Acad Med 1995;70:418-20. 